This item was submitted to Loughborough's Research Repository by the author.

Items in Figshare are protected by copyright, with all rights reserved, unless otherwise indicated.

\title{
On-body measurements of embroidered spiral antenna
}

PLEASE CITE THE PUBLISHED VERSION

http://dx.doi.org/10.1109/LAPC.2015.7366131

PUBLISHER

(c) IEEE

\section{VERSION}

AM (Accepted Manuscript)

\section{PUBLISHER STATEMENT}

This work is made available according to the conditions of the Creative Commons Attribution-NonCommercialNoDerivatives 4.0 International (CC BY-NC-ND 4.0) licence. Full details of this licence are available at: https://creativecommons.org/licenses/by-nc-nd/4.0/

\section{LICENCE}

CC BY-NC-ND 4.0

\section{REPOSITORY RECORD}

Zhang, Shiyu, David Speight, Anastasios Paraskevopoulos, Duarte M. de Sousa Fonseca, Cyril Luxey, W.G. Whittow, and Jon Pinto. 2019. "On-body Measurements of Embroidered Spiral Antenna”. figshare. https://hdl.handle.net/2134/20445. 


\title{
On-Body Measurements of Embroidered Spiral Antenna
}

\author{
Shiyu Zhang, David Speight, Anastasios Paraskevopoulos, Duarte Fonseca, Cyril Luxey ${ }^{\#}$, Will Whittow ${ }^{*}$, Jon Pinto \\ School of Electronic, Electrical and Systems Engineering, Loughborough University, Leicestershire, UK \\ ${ }^{\#}$ EpOC, University of Nice-Sophia Antipolis, Valbonne, FRANCE \\ `BAE Systems’ Applied Intelligence Labs, Gt. Baddow, Chelmsford, UK \\ *W.G.Whittow@lboro.ac.uk
}

\begin{abstract}
This paper presents a compact and flexible embroidered spiral antenna that can be used for wearable applications. The antenna is embroidered by using a state of the art digital embroidery machine with multi-strand conducting thread Liberator ${ }^{\mathrm{TM}}$. The antenna has been measured on a Specific Anthropomorphic Mannequin (SAM) phantom and a real human. The measurement results show that the SAM phantom emulates the dielectric properties of the human body in a wide frequency band from 0.3 to $3 \mathrm{GHz}$. The far-field on-body performance of the antenna has been measured by placing the antenna on the SAM phantom in a tapered Anechoic Chamber. Near-field to far-field transformations have been used to produce the far-field performance including radiation pattern, directivity, rrealised gain and radiation efficiency.
\end{abstract}

Keywords-On-body antenna; spiral antenna; embroidered antenna; wearable antenna; on-body measurement; SAM phantom; near-field to far-field transformation

\section{INTRODUCTION}

Wireless wearable technology is an ever expanding area of research and real products in recent years. The wearable devices have a wide range of applications including wireless medical monitoring, location tracking and mobile communications. Wearable antennas are expected to be implemented into our daily lives without inconvenience or even awareness of the device. Comfort is an important requirement. A smart-cloth with conducting fibres is attractive, as the wearable electronics are embedded in clothes with lightweight, low-profile and network function [1]. Numerous papers have been published concerning flexible yet functional RF components using novel textile-based conducting materials [2]-[8]. Developing the textile-based antennas that can be mass-manufactured by using industrial-standard textile fabrication techniques will reduce the cost and increase the popularity of fully fabric wearable antennas.

Wideband antennas are ideal candidates for wearable communications as on-body antennas often suffer from the detuning due to the presence human body. Spiral antennas are known for their wide bandwidth and low-profile qualities. Matthews et al. presented a wearable spiral antenna with the discussion of required performance of antennas for both civil and military applications in [9]. Textile manufacturing techniques can be used for fabricating wearable spiral antennas with the advantages of flexibility and integration into clothing [10]. Integrating the antenna into the clothing alleviates the requirements for miniaturising the antenna as long as it fits on the torso. The repeatability of embroidered microstrip patch antennas has been investigated and has showed its potential for mass-manufacturing [11]. Wang et al. demonstrated an embroidered broadband spiral antenna with an integrated balun in [12] but without on-body pattern measurements. The performance of embroidered antennas is affected by embroidery stitch direction and spacings. In general embroidered antennas benefit from smaller stitch spacings and stitches aligned parallel to current direction [13], [14]. The performance of conducting textile materials at high frequencies have been characterised in [15], [16].

This paper has investigated an embroidered spiral antenna and compared its performance on both a Specific Anthropomorphic Mannequin (SAM) phantom and a real human chest. Previous research indicated that the position of the antenna on the human body should be accounted for when designing wearable antennas as the interaction between the device and the body is strongly affected by the body shape [17]-[19]. The antenna placed on the human chest was simulated using CST Microwave Studio (CST). The antenna design was exported as a graphic format to the digital embroidery machine (model: Entrepreneur Pro PR1000e) at Loughborough University. Conductive thread Liberator ${ }^{\mathrm{TM}}$ [20] was used. The broadband performance of the spiral antenna were measured and compared to simulated results to confirm the viability of the antenna for on-body use.

\section{SPIRAL ANTENNA DESIGN}

The spiral antenna was designed as an Archimedean spiral with the exterior diameter of $208 \mathrm{~mm}$, to operate in the frequency band ranging from $300 \mathrm{MHz}$ to $3 \mathrm{GHz}$. In the simulations, the spiral antenna was placed $20 \mathrm{~mm}$ distance from a $400 \mathrm{~mm} \times 400 \mathrm{~mm} \times 50 \mathrm{~mm}$ cuboid homogeneous block with $\varepsilon_{r}=40, \mu_{r}=1$ and $\sigma=1 \mathrm{~S} / \mathrm{m}$ to emulate the dielectric properties of human body [19]. The $20 \mathrm{~mm}$ separation emulated a layer of clothing and air gap between the antenna and a human body. Note, in the simulations, the dielectric properties of clothing were not included. The design for the antenna in CST can be seen in Fig. 1. The electrical property of the spiral was modelled as the conducting thread Liberator $^{\mathrm{TM}}$ with a conductivity of silver with a thickness of 1 micron.

The simulated $|\mathrm{S} 11|$ of the antenna on the cuboid phantom over the frequency ranging from 0.3 to $3 \mathrm{GHz}$ is shown in Fig. 2 for four different antenna-body separations. The antenna has an $|\mathrm{S} 11|$ below $-6 \mathrm{~dB}$ for almost the entire frequency range above $0.5 \mathrm{GHz}$. The $|\mathrm{S} 11|$ could be improved by terminating the ends of the spiral. The far-field simulation is shown in Fig. 3 . The directivity pattern clearly shows that the effect of the chest phantom, the radiation pattern from $-90^{\circ}$ to $+90^{\circ}$ is distorted and the antenna becomes more directional with a directivity of approximately $9 \mathrm{dBi}$ at $2.4 \mathrm{GHz}$. The simulated 
radiation (total) efficiency at $2.4 \mathrm{GHz}$ at different antennacuboid separations are: $2 \mathrm{~mm}=5.4(4.6 \%) ; 7 \mathrm{~mm}=21.8$ (16.9)\%; $10 \mathrm{~mm}=35.1(27.5) \%$ and $20 \mathrm{~mm}=67.9(52.7) \%$.

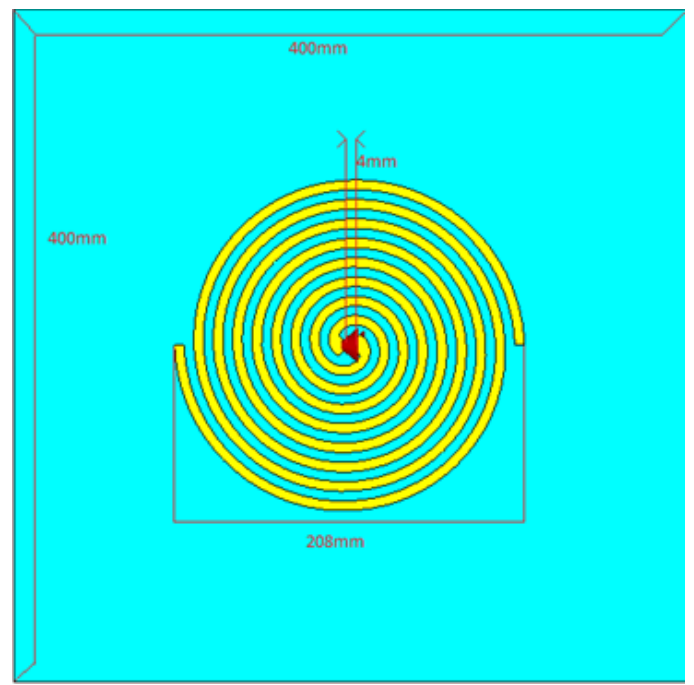

Fig. 1. Spiral antenna simulation design in CST

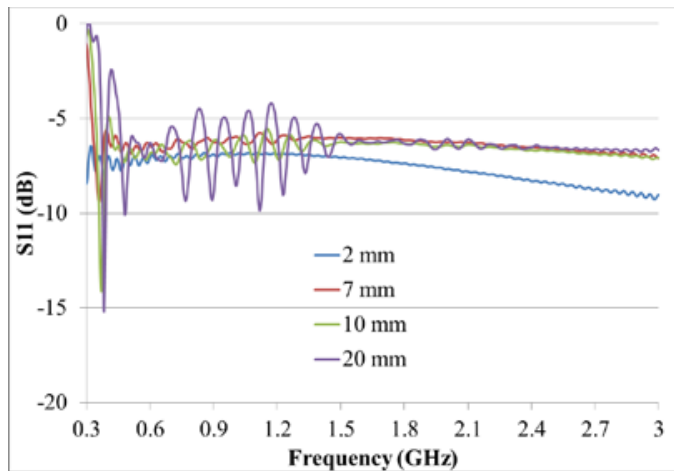

Fig. 2. Simulated S11 of spiral antenna different distances from cuboid phantom

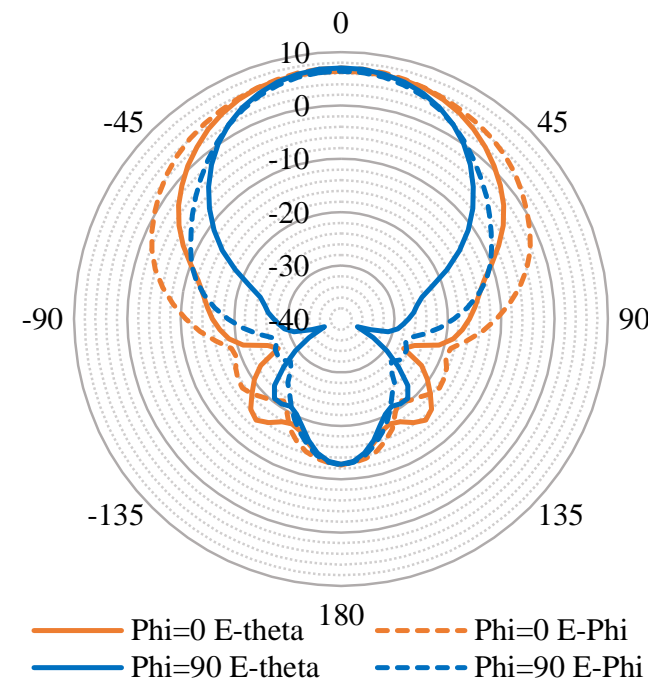

Fig. 3. Simulated directivity pattern of the spiral antenna at $2.4 \mathrm{GHz}$

\section{FABRICATION OF EMBROIDERED SPIRAL ANTENNA}

Digital embroidery machine Entrepreneur Pro PR1000e was used to fabricate the spiral antenna. The embroidered stitch direction was optimised to follow the current flow. Four parallel spiral lines were embroidered to increase the physical robustness. Despite increasing the stitch spacing and lowering the stitch density, the antenna required over 12000 individual stitches in the best case, representing more than $120 \mathrm{~m}$ of Liberator thread, making it costly and time consuming to fabricate. To lower the expense of the antenna, the stitching of the antenna was manually controlled. Approximately 4500 stitches were used to fabricate the spiral. This saved $75 \mathrm{~m}$ of conducting thread ( $\sim £ 1$ per meter) and two hours of fabrication time. The embroidered spiral antenna is shown in Fig. 4.

A $50 \Omega$ flexible coaxial cable was used for feeding the embroidered spiral antenna. The two arms of the spiral were soldered on the inner probe and outer shield respectively by using low temperature solder. A $50 \Omega$ SMA connector was connected to the other end of the cable for connecting test port.

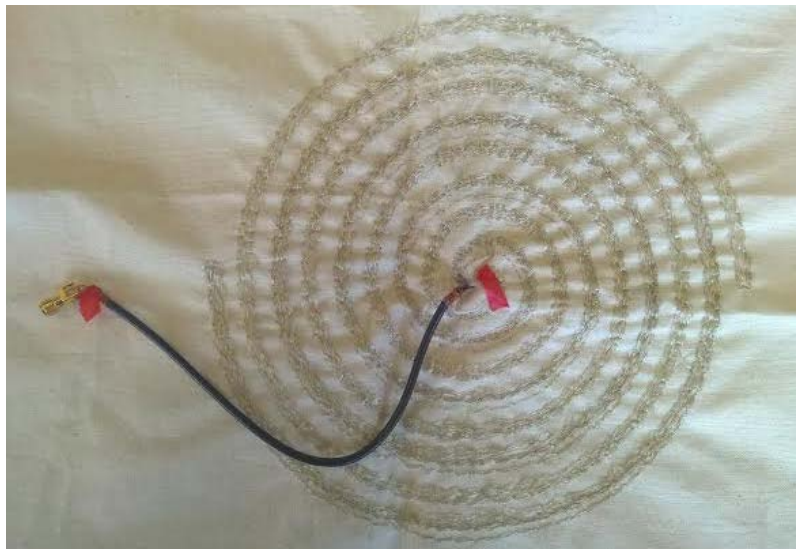

Fig. 4. Embroidered spiral antenna

\section{ON-BODY ANTENNA MEASUREMENT}

The embroidered spiral antenna was measured against a human chest as shown in Fig. 5. The antenna was flattened and placed against the chest. A measurement of the same antenna in free space was made for comparison. The measured $|\mathrm{S} 11|$ results are shown in Fig. 6.

The performance of the spiral antenna is variable over the frequencies from 0.3 to $1.7 \mathrm{GHz}$ with the $|\mathrm{S} 11|$ lower than -5 $\mathrm{dB}$. Overall, the antenna against the chest operates below the -4 $\mathrm{dB}$ across 0.3 to $3 \mathrm{GHz}$ frequency range. Moreover, at high frequencies ranging from 1.6 to $3 \mathrm{GHz}$, the spiral antenna had better $|\mathrm{S} 11|$ when placed on the chest compared to in free space. Fig. 6 shows the mismatch of the embroidered spiral antenna above $1.2 \mathrm{GHz}$ which would affect the radiation performance. It was noticed that the embroidery process for the spiral antenna was complicated and prone to error. It can be clearly seen in Fig. 4 that the substrate is significantly warped from the embroidery, thus warping the antenna itself. This inevitably introduces differences compared to the ideal simulation case as is true for all wearable antennas. 


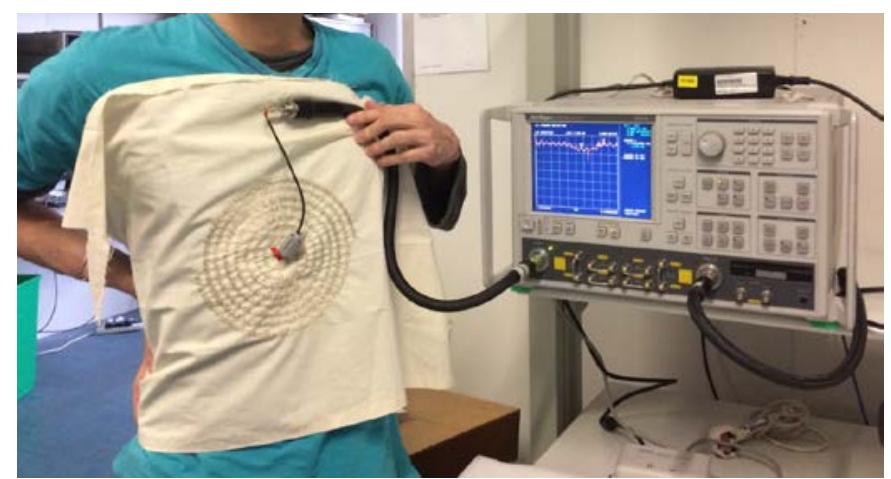

Fig. 5. Measured set up for the embroidered spiral antenna on-body measurement

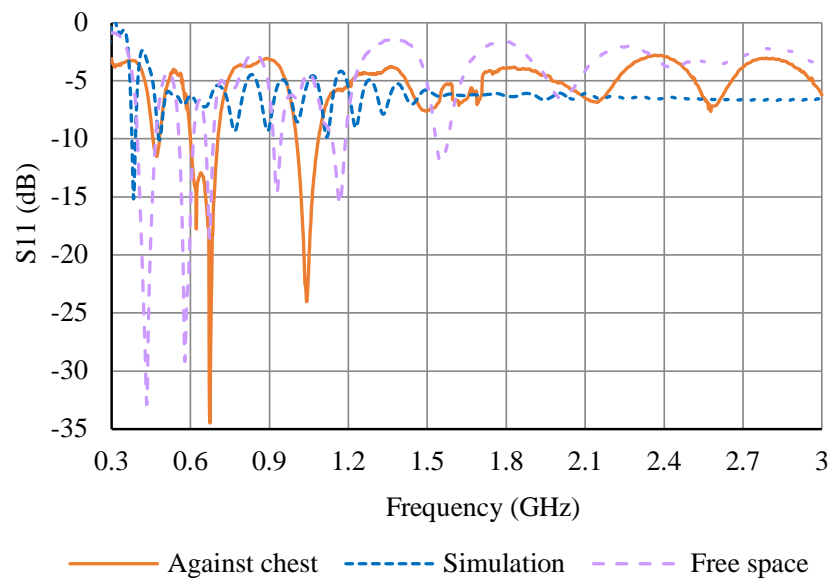

Fig. 6. Measured S11 of embroidered spiral antenna placed against human chest and in free space compared to simulation at $2 \mathrm{~cm}$ separation

A series of ferrite beads were used to improve the feeding from the coaxial cable to the spiral due to the lack of balun for the antenna. Two different ferrite beads were tested and gave similar $|\mathrm{S} 11|$ results.

\section{Antenna MEASUREMENT ON SAM PHANTOM}

The far-field performance of the embroidered spiral antenna was measured in a tapered Anechoic Chamber at Loughborough University. The antenna was attached to the surface of a SAM torso phantom with minimal separation. The phantom is made of solid homogenous carbon loaded silicon material for a broad frequency range of 0.3 to $6 \mathrm{GHz}$ and there is no plastic shell. The permittivity and conductivity of the phantom at selected frequencies are given in Table I. Note the phantom did not include arms or legs. For the antenna on-body characterisation, we employed a novel near-field scanning technique with the probe scanning in the $\mathrm{Y}$-axis and the antenna under test (AUT) was rotated in the azimuth plane. After transformation of the recorded near-field to far-field, the on-body antenna efficiency as well far-field patterns in the two principal planes were calculated. The far-field coordinate system (roll-over-azimuth) of the measurement is shown in Fig. 7.

The measured S11 of the antenna on the phantom is plotted in Fig. 8 and compared with the measured S11 result of the antenna against human chest. The results show that the phantom is a very good approximation for the human body for a wide frequency range.

TABLE I. DiELECTRIC PROPERTIES OF PHANTOM

\begin{tabular}{|c|c|c|}
\hline Frequency (GHz) & Relative permittivity & Conductivity (S/m) \\
\hline 0.481 & 50.1 & 0.61 \\
\hline 0.974 & 42.6 & 0.94 \\
\hline 1.458 & 39.0 & 1.23 \\
\hline 1.972 & 36.8 & 1.55 \\
\hline 2.412 & 35.4 & 1.81 \\
\hline 2.950 & 33.9 & 2.14 \\
\hline
\end{tabular}

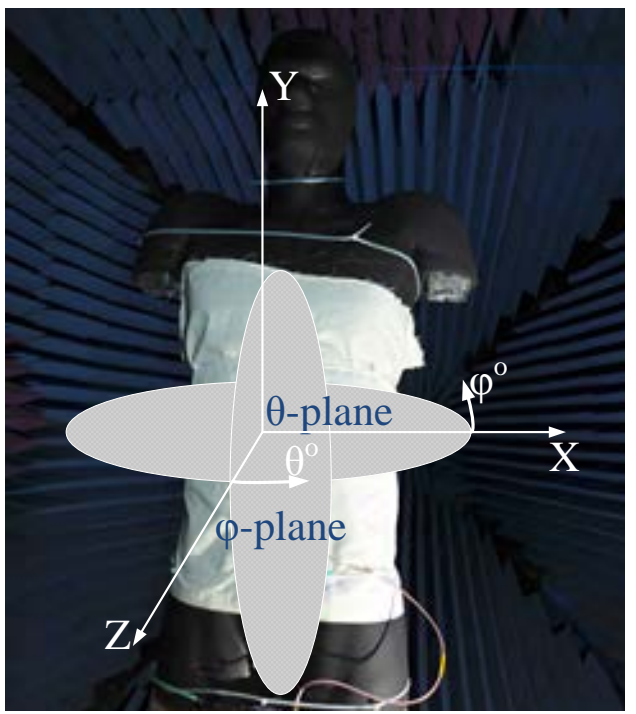

Fig. 7. The embroidered spiral antenna attached to the SAM torso phantom in tapered anechoic chamber with coordinates

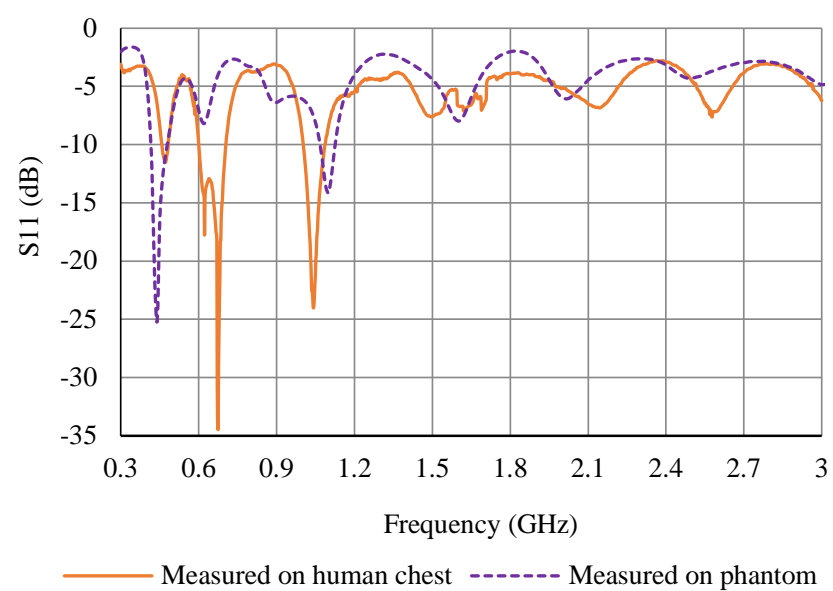

Fig. 8. Measured S11 of the embroidered spiral antenna on human chest and phantom chest

The far-field performance of the antenna in the frequency band ranging from 1.6 to $2.6 \mathrm{GHz}$ is shown in Table II. It can be seen that the antenna gain varied from approximately 0 to $4 \mathrm{dBi}$ across the measured frequency range. The antenna radiation efficiency is approximately $10 \%$ increasing to $25 \%$ from 1.6 to $2.6 \mathrm{GHz}$. At higher frequencies, the effective 
separation in terms of wavelengths between the antenna and the body increases. Furthermore, the skin depth becomes smaller and therefore conductor losses increase.

TABLE II. MEASURED FAR-FIELD PERFORMANCE OF THE EMBROIDERED SPIRAL ANTENNA ON THE PHANTOM. NOTE THE RADIATED GAIN AND RADIATED EFFICIENCY DO NOT INCLUDE THE S11 MISMATCH

\begin{tabular}{|c|c|c|c|}
\hline $\begin{array}{c}\text { Frequency } \\
\text { (GHz) }\end{array}$ & $\begin{array}{c}\text { Directivity } \\
\text { (dBi) }\end{array}$ & $\begin{array}{c}\text { Radiated (IEEE) } \\
\text { Gain (dBi) }\end{array}$ & $\begin{array}{c}\text { Radiation } \\
\text { Efficiency (\%) }\end{array}$ \\
\hline 1.6 & 9.36 & 0.29 & 12.4 \\
\hline 1.7 & 9.41 & 0.13 & 11.8 \\
\hline 1.8 & 9.45 & 1.69 & 16.8 \\
\hline 1.9 & 9.70 & 2.24 & 18.0 \\
\hline 2.0 & 9.57 & 2.69 & 20.5 \\
\hline 2.1 & 9.97 & 2.94 & 19.8 \\
\hline 2.2 & 10.14 & 3.12 & 19.9 \\
\hline 2.3 & 9.42 & 1.99 & 18.1 \\
\hline 2.4 & 9.98 & 3.00 & 20.0 \\
\hline 2.5 & 10.00 & 3.93 & 24.7 \\
\hline 2.6 & 10.12 & 3.40 & 21.3 \\
\hline
\end{tabular}
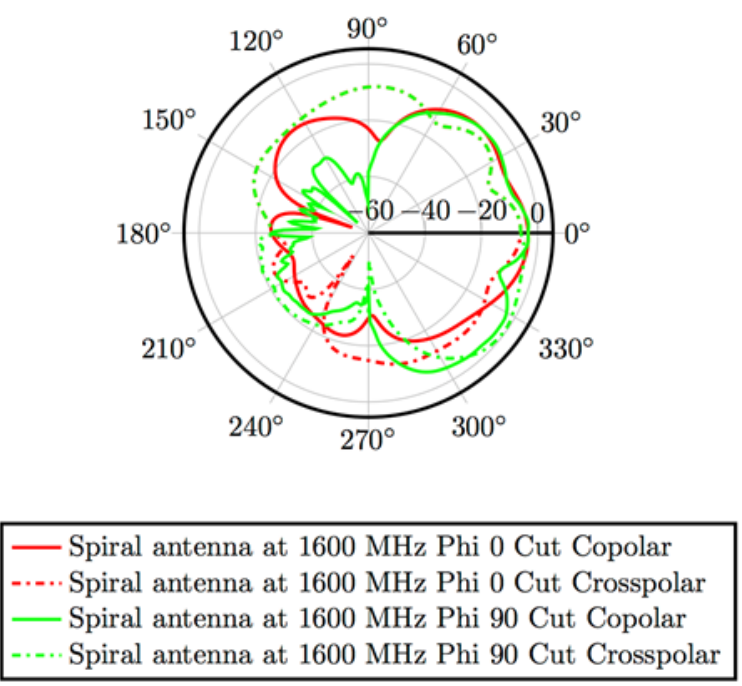

Fig. 9. Radiation pattern of the embroidered spiral antenna at $1600 \mathrm{MHz}$
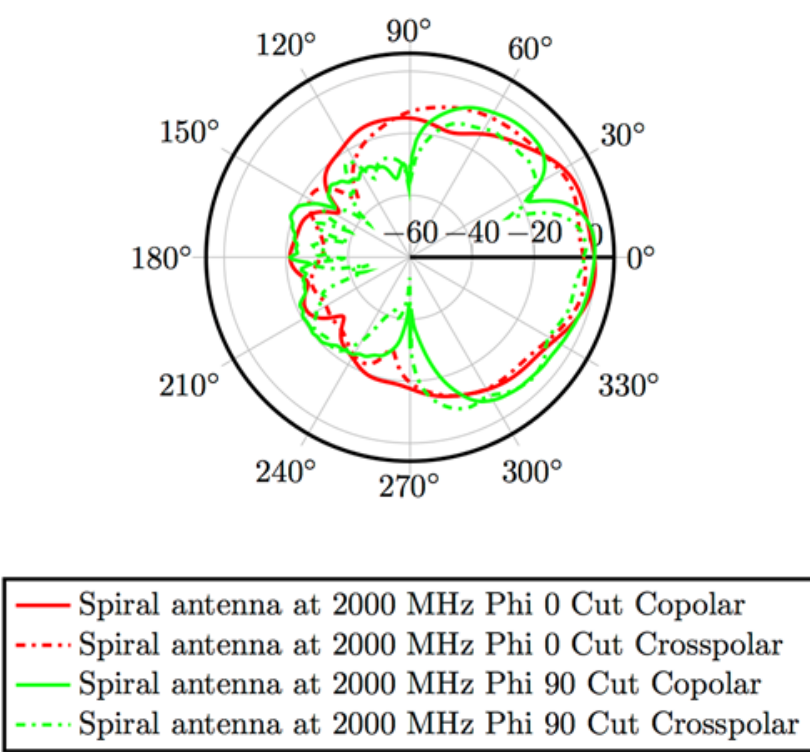

Fig. 10. Radiated gain pattern of the embroidered spiral antenna at $2000 \mathrm{MHz}$

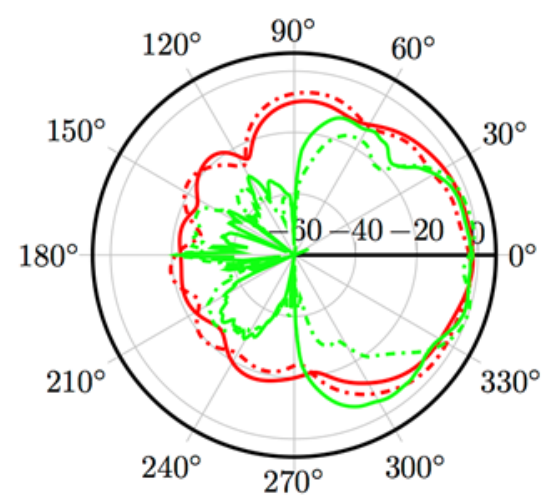

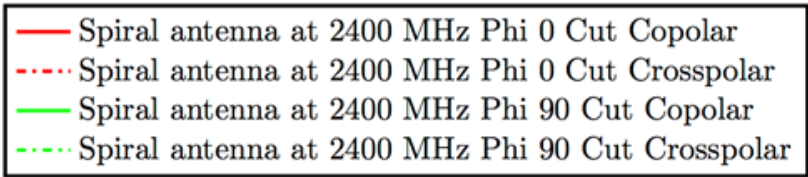

Fig. 11. Radiated gain pattern of the embroidered spiral antenna at $2400 \mathrm{MHz}$

The radiation patterns of the embroidered spiral antenna on phantom at frequencies of $1600 \mathrm{MHz}, 2000 \mathrm{MHz}$ and 2400 $\mathrm{MHz}$ are shown in Fig. 9 to Fig. 11. It is clear in all the cases that the far-field pattern is distorted by the body presence between 90 and 270 degrees. It is noticed that the cross polarized component is increased. As the frequency of operation increases the antenna becomes more directive with more radiated energy being directed off the body.

\section{CONCLUSIONS}

The paper has presented the comparison between on-body and on-SAM phantom measurement of the embroidered spiral antenna. The antenna was simulated against a chest phantom. The simulation results showed the return loss of the antenna were generally better than $6 \mathrm{~dB}$ from 0.5 to $3 \mathrm{GHz}$. The spiral antenna was embroidered by using conducting thread. The embroidered antenna was flexible and light-weight which could easily be integrated into clothing. The measured $|\mathrm{S} 11|$ results on SAM phantom chest showed good agreement with the real human chest. The results show that the viability of using the SAM phantom to emulate the body effects in wearable antenna measurements.

The measured far-field results showed that the radiation efficiency of the embroidered antenna was approximately $10 \%$ to $25 \%$ from 1.6 to $2.6 \mathrm{GHz}$ when attached on chest. This demonstrates the potential of this embroidered spiral antenna in Industrial, Scientific and Medical (ISM) radio bands applications.

The ultimate purpose of a textile-based flexible wearable antenna is to replace antennas on conventional portable wireless devices. To this end, future work should include studies into overcoming the body effect on wearable antennas radiation performance, the practical position for wearable antennas and how to conceal antennas inside such as logo antennas [21] or the inner lining of clothing [22]. Convincing 
consumers that the antenna is safe and effective is necessary to develop the technology and to have society adopt it.

\section{ACKNOWLEDGEMENT}

The authors would like to thank the Defence Science and Technology Laboratory (DSTL) for providing the SAM phantom.

\section{REFERENCES}

[1] E. R. Post, M. Orth, P. R. Russo, and N. Gershenfeld, "E-broidery: Design and fabrication of textile-based computing," IBM Systems Journal, vol. 39, no. 3.4, pp. 840-860, 2000.

[2] T. Acti, S. Zhang, A. Chauraya, W. Whittow, R. Seager, T. Dias, and Y. Vardaxoglou, "High performance flexible fabric electronics for megahertz frequency communications," in Loughborough Antennas \& Propagation Conference (LAPC), 2011, pp. 1-4.

[3] L. Zhang, Z. Wang, and J. L. Volakis, "Textile Antennas and Sensors for Body-Worn Applications,” IEEE Antennas and Wireless Propagation Letters, vol. 11, pp. 1690-1693, 2012.

[4] S. Zhang, R. D. Seager, A. Chauraya, W. G. Whittow, and J. C. Vardaxolgou, "Textile Manufacturing Techniques in RF Devices," in Loughborough Antennas \& Propagation Conference (LAPC), 2014.

[5] R. D. Seager, J. Bowman, R. Philpott, A. Chauraya, M. Broughton, and N. Nimkulrat, "Fabric based frequency selective surfaces using weaving and screen printing," Electronics Letters, vol. 49, no. 24, pp. 1507-1509, Nov. 2013.

[6] A. Chauraya, R. Seager, W. Whittow, S. Zhang, and Y. Vardaxoglou, "Embroidered Frequency Selective Surfaces on textiles for wearable applications," in Loughborough Antennas \& Propagation Conference (LAPC), 2013, no. November, pp. 388-391.

[7] W. G. Whittow, A. Chauraya, J. C. Vardaxoglou, Y. Li, R. Torah, K. Yang, S. Beeby, and J. Tudor, "Inkjet-Printed Microstrip Patch Antennas Realized on Textile for Wearable Applications," IEEE Antennas and Wireless Propagation Letters, vol. 13, pp. 71-74, 2014.

[8] R. D. Seager, A. Chauraya, S. Zhang, W. Whittow, and Y. Vardaxoglou, "Flexible radio frequency connectors for textile electronics," Electronics Letters, vol. 49, no. 22, pp. 1371-1373, Oct. 2013.

[9] J. C. G. Matthews, B. P. Pirollo, A. J. Tyler, and G. Pettit, "Wide-band Body Wearable Antennas," in Wideband, Multiband Antennas and Arrays for Defence or Civil Applications, Institution of Engineering and Technology Seminar on, 2008, p. 111,128.

[10] J. C. G. Matthews and G. Pettitt, "Development of flexible, wearable antennas,” in 3rd European Conference on Antennas and Propagation (EuCAP), 2009, p. 273,277.

[11] S. Zhang, A. Chauraya, W. Whittow, R. Seager, T. Acti, T. Dias, and Y. Vardaxoglou, "Repeatability of embroidered patch antennas," in Loughborough Antennas \& Propagation Conference (LAPC), 2013, no. November, pp. 140-144.

[12] Z. Wang, L. Z. Lee, and J. L. Volakis, "A 10:1 bandwidth textile-based conformal spiral antenna with integrated planar balun,” in IEEE Antennas and Propagation Society, AP-S International Symposium (Digest), 2013, pp. 220-221.

[13] S. Zhang, A. Chauraya, W. Whittow, R. Seager, T. Acti, T. Dias, and Y. Vardaxoglou, "Embroidered wearable antennas using conductive threads with different stitch spacings," in Loughborough Antennas \& Propagation Conference (LAPC), 2012, pp. 1-4.

[14] R. Seager, S. Zhang, A. Chauraya, W. Whittow, Y. Vardaxoglou, T. Acti, and T. Dias, "Effect of the fabrication parameters on the performance of embroidered antennas,” IET Microwaves, Antennas \& Propagation, vol. 7, no. 14, pp. 1174-1181, Nov. 2013.

[15] D. Cottet, J. Grzyb, T. Kirstein, and G. Troster, "Electrical characterization of textile transmission lines," Advanced Packaging, IEEE Transactions on, vol. 26, no. 2, pp. 182-190, 2003.
[16] K. Karlsson and J. Carlsson, "Wideband characterization of fabrics for textile antennas," in 6th European Conference on Antennas and Propagation (EuCAP), 2012, pp. 1358-1361.

[17] W. G. Whittow, C. J. Panagamuwa, R. M. Edwards, J. C. Vardaxoglou, and P. McEvoy, "A study of head worn jewellery, mobile phone RF energy and the effect of differing issue types on rates of absorption," in The First European Conference on Antennas and Propagation (EuCAP), 2006

[18] W. G. Whittow, C. J. Panagamuwa, R. M. Edwards, and J. C. Vardaxoglou, "The SAR Effects of Popular Jewellery on the Human Head," in The Second European Conference on Antennas and Propagation ( EuCAP ), 2007.

[19] D. Titz and C. Luxey, "The Bra-tenna: A novel body-mounted antenna for off-body communications,” in 2014 Loughborough Antennas and Propagation Conference (LAPC), 2014, pp. 239-243.

[20] "Liberator Fiber." [Online]. Available: http://www.metalcladfibers.com/liberator-fiber/. [Accessed: 10-Jun2015].

[21] W. G. Whittow, "Antenna emblems reshaped as icons and esthetic logos (Aerial)," Microwave and Optical Technology Letters, vol. 55, no. 8, pp. 1711-1714, 2013

[22] J. Roh, Y. Chi, J. Lee, Y. Tak, S. Nam, and T. J. Kang, "Embroidered Wearable Multiresonant Folded Dipole Antenna for FM Reception," IEEE Antennas and Wireless Propagation Letters, vol. 9, pp. 803-806, 2010 